\title{
Energy efficiency strategies to improve productivity and competitiveness of the EU countries
}

\author{
A. Martínez ${ }^{1}$, S. Valero $^{1}$, C. Senabre ${ }^{1}$ and E. Velasco ${ }^{1}$ \\ ${ }^{1}$ Department of Mechanical and Energy Engineering \\ E.T.S.I.I., Miguel Hernandez University \\ Elche, 03202 Alicante (Spain) \\ Phone/Fax number:+0034 96 665890, e-mail: alberto.martinez@umh.es,
}

\begin{abstract}
.
Energy harmonization of the electricity market, infrastructure and decision-making in energy policy are a complex problem given the great technical contrasts, geopolitical diversity and different economic situations in the EU countries. Although the European authorities are taking steps, it will take a long time before an interconnected and harmonized electricity market in Europe is reached. The major challenges to face in the electricity sector in the EU are issues such as: the development of energy storage, as well as the intelligent network management, or demand-side participation by end-users in real time. The persistent dependence of fossil fuels on the electric mix remains a reality that dampens $\mathrm{CO}_{2}$ emissions and limits the use of clean technologies.
\end{abstract}

At the same time, it is necessary to obtain a reliable data structure to obtain the reliable information with which to make decisions. Moreover, to analyze the information conecting different dimensions such as: energy sustainability, protection of the atmosphere, water and territory management. The present paper analyzes the appropriate variables for energy policy decision making, while alizing the behavior of several EU countries.

\section{Key words}

Energy, competitiveness, electricity, productivity, efficiency.

\section{Introduction}

The EU's approach to the climate and energy objectives [1] for the coming decades is well known: by 2020 , to reduce greenhouse gas emissions by at least $20 \%$ compared to 1990 levels; to get $20 \%$ of energy from renewable sources and improve energy efficiency by $20 \%$. The goals for 2030 are: to reduce greenhouse gas emissions by $40 \%$, to obtain at least $27 \%$ of energy from renewable sources; to increase energy efficiency by $27-30 \%$ and to add $15 \%$ of electricity generated in the EU that must be able to be transported to other Member States in order to improve the interconnections between the different countries. Finally, by 2050 to reduce greenhouse gas emissions by $80-95 \%$ from levels measured in 1990.

At the same time, EU policies [2] are aimed to reduce the dependence on fossil fuels (a culprit component of the still persistent external energy dependency in terms of: oil, coal, gas ...). Then, it should be created policies for replacing traditional technologies by renewable technologies. But also, a boost of energy efficiency that allows a decoupling between GDP and primary energy consumption. Regarding to the transport sector, a sustained growth of this activity is expected up to 2030 . Therefore, this justifies the fact that the next directives on emissions in this sector will focuse more on efficiency. Moreover, it will allow acceleration during these years the decoupling between activity and energy consumption in that sector. Thus, in the electricity sector, a significant increase in final energy demand is expected, from $20 \%$ of the source in 2005 to $28 \%$ in 2050 (Figure 1).
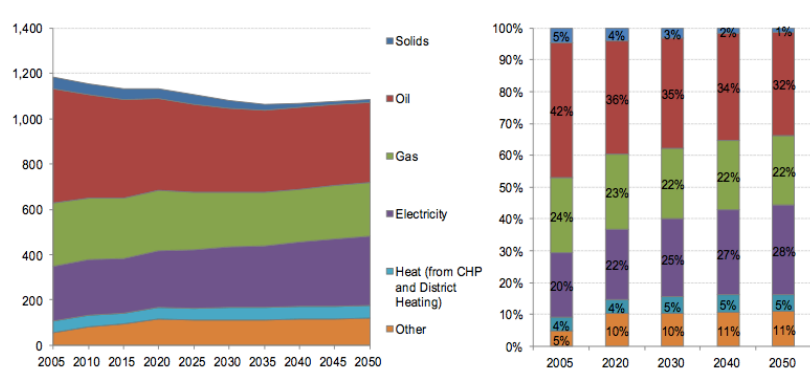

Figure 1. Evolution of final energy demand of fuel (Mtoe - left, shares - right) - Source: EU Reference Scenario 2016 Energy, Transport And Ghg Emissions Trends To 2050 [2]

On the other hand, measures to liberalize the electricity market in the EU have a limited path, due to the restrictions of the electricity market and the still existing technical restrictions that will delay the establishment of a single market for electricity. Due to the importance that the electricity sector will acquire in the coming decades in terms of: deployment of the electric vehicle infrastructure, the development of smart grids, real-time 
participation of market demand with distributed generation or non, the present work analyzes the different variables that are used in the evaluation. As well as: the adequacy, the scope and the analisys of these variables. In addition, access to electricity by users and in particular price, volatility and their impact on the competitiveness of enterprises, will be very important variables to take into account in the definition of energy policies of EU countries.

\section{Indicators for aggregation model}

The three important characteristics to be taken into account in determining the most appropriate indicators that allow discriminating the controlled variables are the following: firstly, a broad periodicity must be defined, allowing a wide range of observation. Secondly, to have up-to-date and reliable information that allows comparison between different countries by obtaining data with the same methodology. Thirdly, the data must have a sufficient level of disaggregation that allows observing patterns of behavior or patterns in the series that compose them. These indicators will be crucial for grouping by families and controlling the most appropriate variables to determine the search for abnormal behaviors or even patterns of behavior in different policies

The determination of these variables firstly challenges their suitability [3] to the different economic, energy, territorial and social conjunctures of the different countries, ie not all variables will be the most appropriate to carry out an analysis of the energy situation in the different nations taking into account the concept of local sustainability [4]. For example, a region such as Western Europe, where there is a large dependence on energy from abroad and a contribution from the major electricity sector to the final energy available, will need to evaluate variables that will have nothing to do with those needed for the Central African region, where electrical dependence is much lower. On the other hand, Somalia, a country in which agriculture accounts for $60.2 \%$ [5] of its GDP has a completely different energy situation to the United Kingdom whose agriculture represents about 1\% [6] of GDP. Therefore, we should no longer talk so much about the variables of energy sustainability, but about families of sustainability variables that will be appropriate to different countries. From the definition and analysis of adequate prior indicators, it will be possible to propose the most determinant variables that allow, for example, to control the energy policies in the different nations.

As mentioned above, we must first establish groupingcriteria in families, appropriate to the situations of the countries to be analyzed. For this purpose, different models [7-9] have been studied, using discriminatory indicators to make appropriate comparisons between different countries, such as: Population, GDP (US \$), GDP per capita, Contribution of productive sectors to GDP, Contribution of the Industrial Sector to GDP (\% of GDP), Freight transport activity, Distance traveled per capita, Household per capita, Gross value added of the manufacturing sector, Total Primary Energy Production/
Gross Inland Consumption (\%), Accessible energy (US \$ / $\mathrm{kWh})$, Population access to water (\%), Level of inequality in wages, Energy intensity of Economy (ktep / US \$), Emission intensity ( $\left.\mathrm{kCO}_{2} / \mathrm{US} \$\right), \mathrm{CO}_{2}$ emissions per capita.

Economies based on productive sectors related to industry (industrial sector contribution to GDP) will be much more lavish in energy expenditure than others based on agriculture. Then, the comparison between countries with similar GDP distributions by sectors will be a very important criterion for grouping the variables to be used. As can be seen, the countries under study have a very similar distribution of GDP, as shown in Figure 2.

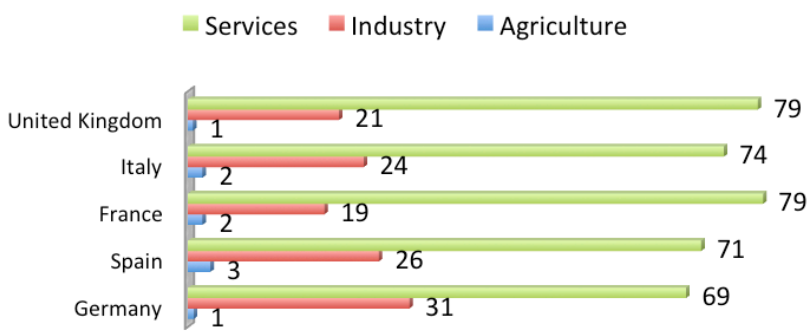

Figure 2. GDP by Sector 2012 (\%) Source: CIA[5], IMF [11]

From the point of view of infrastructures, it is noteworthy that economies with a similar structure in the transport sector (evaluating indicators of freight transport activity or distance traveled per capita, or even $\mathrm{CO}_{2}$ emissions from that sector) will also facilitate homogenization in the comparison of prices and energy consumption. Finally, from a territorial conjuncture point of view: the degree of self-sufficiency of energy, as well as the distribution of the population (per capita housing area, residential and tertiary sector), will also allow to establish similarities that will facilitate the comparison of variables and to obtain patterns of behavior.

Population and per capita income will be important indicators for the grouping by families of the countries to be evaluated. In this case, the aspects related to access to electricity, water and per capita housing are similar, but in terms of per capita income, there are some differences, which would lead to a possible differentiation into two groups: on the one hand Spain and Italy and on the other France, Germany and UK. However, a maximum will be established later, from which all countries with a lower indicator will enter the same family. But also, it will be established ratios of energy variables and of competitiveness and productivity using the population. It will be possible to cushion the effect of these variables on the population, which would discard the joint analysis of Germany and Spain. But also, taking into account ratios energy variables and of competitiveness and productivity using the population, will let to cushion the effect of these variables on the population, which would be discarded in the joint analysis of Germany and Spain.

Therefore, the comparable countries will be those that have their parameters of conjuncture framed in clusters based on the previous indicators. The range of countries defined for the study and based on these parameters are: Germany, France, Italy, United Kingdom and Spain. 


\section{Competitiveness and productivity of the economies}

It is necessary to evaluate variables related to competitiveness, such as: the relation between per capita income and the price of electricity in the domestic-services and industrial sector. The control of these variables allows, on the one hand, measuring the country's productivity, related to the price of electricity. On the other hand, analyzing the degree of competitiveness of the sector. It is important to emphasize that countries with higher GDP, being related to the population through per capita income, will cushion the existing population distortion among the countries under study. Moreoverer, the real prices in the GDP will allow inflation, as a tool to homogenize the data of each year allowing inter-annual comparisons.
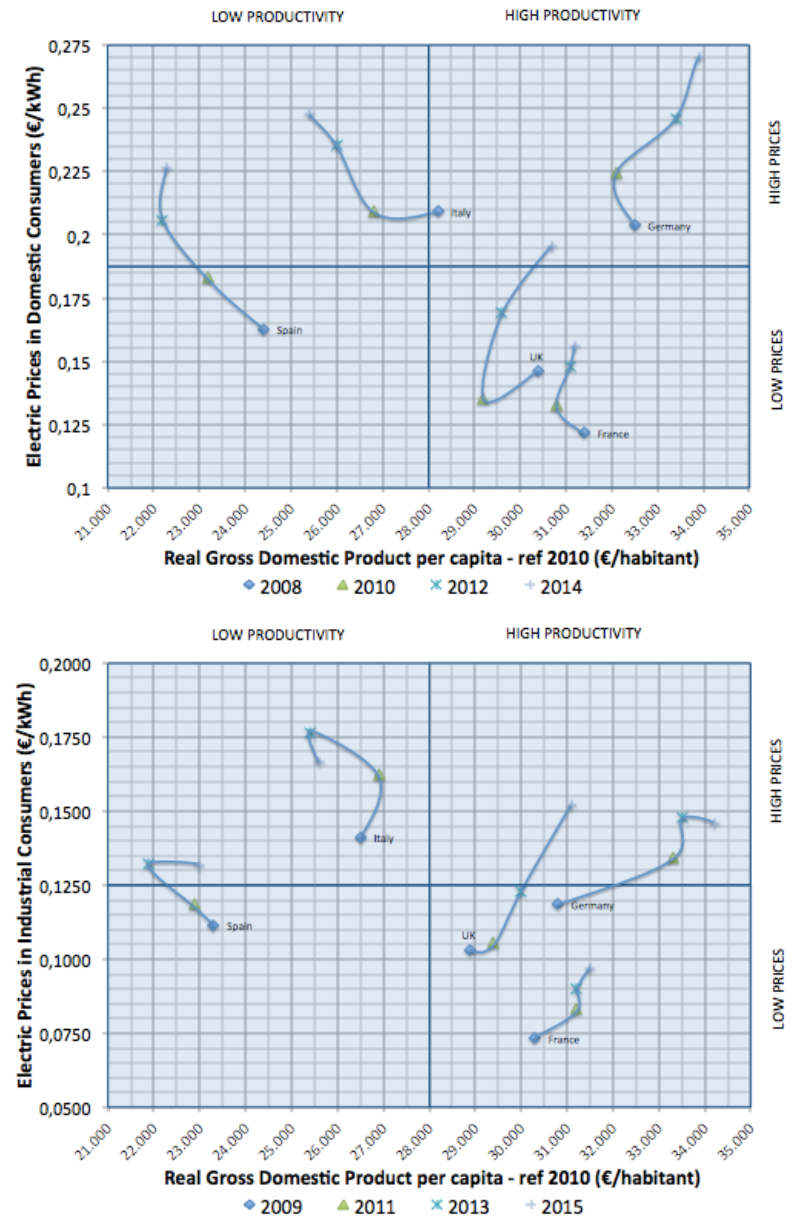

Figure 3. Electric Prices in Domestic Consumers - Up and Industrial Consumers - Down $(€ / \mathrm{kWh})$ and Real Gross Domestic Product per capita base 2010 ( $€ /$ habitant). Source: Eurostat [6]

As shown in Figure 3, four competitiveness zones can be established on the chart, where there are the countries under study. Logically, policies must be focused on low prices of electricity and high productivity of the economies. France and UK are focused in these policies. The most complicated area from the point of view of competitiveness will be that of low productivity and high prices of electricity. This is the case of Spain and Italy. Whose tendency in the last year 2015 has been to reduce prices only in the industrial sector, considering slight increases in productivity. In service sector, Spain and Italy continue to evolve in a direction towards low productivity.

\section{A. Services Sector}

The weight of final energy consumption in the services sector (including domestic and residential, agriculture and fishing) is mainly engaged in electricity and gas (between $70-90 \%$ of total) and, to a lesser extent, oil products. These are the reason why the analysis is focused on these sources (Figure 4). The UK case is interesting because Gas consumption is almost double that of electricity in the services sector, as in Italy. However, in Spain, the consumption of gas is less than the half of electricity consumption in services sector.

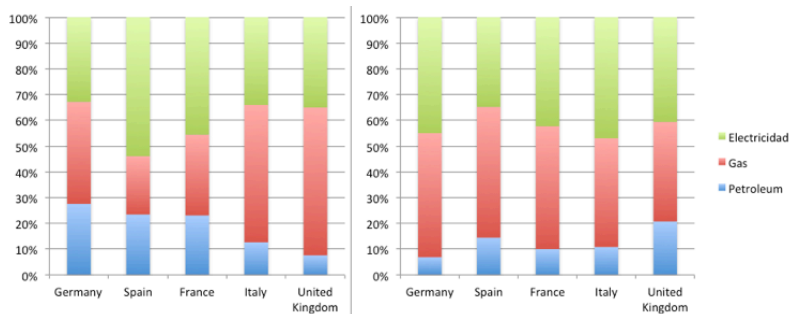

Figure 4. Share of energy source on Final Energy Consumption in Residential and Services Sector - Left and Industrial Sector Right (\%) 2014. Source: Eurostat [6]

Analyzing the participation of the electricity sector in the final energy consumption of the countries under study, as shown in Figure 5, four zones can be defined depending on the level of Effciency and Productivity. The most desirable zone would be the one where is the UK, with low electricity prices and also reduced energy consumption. However, in sectors studied in this case: residential, domestic and services, consumption from other sources, such as natural gas and oil products, must also be taken into account (see Figure 4). For example in Spain, there is possible increment in the use of natural gas as an alternative to electricity due to its low price per $\mathrm{kW} / \mathrm{h}$ and its still low share in the final energy consumption of that country.

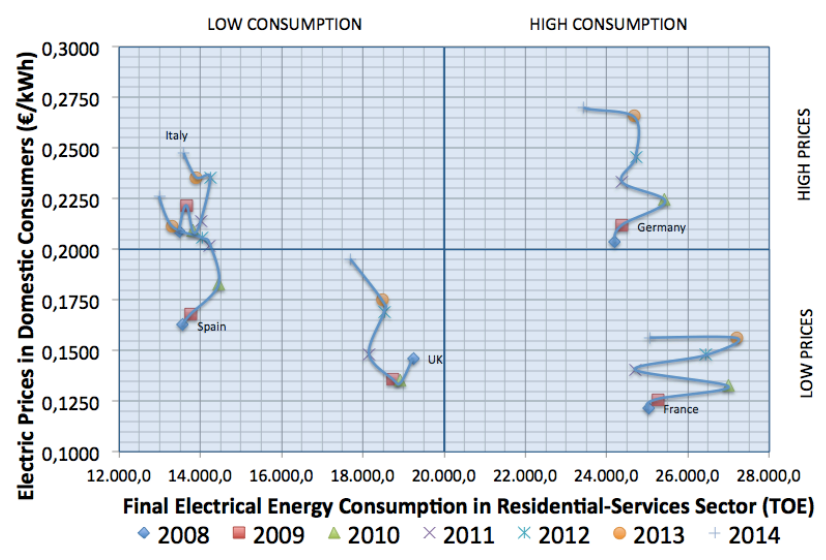

Figure 5. Electric prices in Domestic Consumers (excl. IVA) $(€ / \mathrm{kWh})$ and Final Electrical Energy Consumption in Residencial-Services Sector (TOE). Source: Eurostat [6]

Energy efficiency is obtained in Figure 6. On the one hand, the gross value added of trade and services sector 
per capita, which would represent the productivity variable, and on the other hand the final consumption of energy (gas + electricity + oil products) divided by the gross value added in that sector. Spain and Italy in this case acquire a prominent place of energy efficiency but with a low productivity. In contrast, United Kingdom and France have a tendency towards high efficiency with high productivity of the sector. Finally, although Germany has a high productivity it is placed in a quadrant, where the energetic system of the sector has not a high level of efficiency.

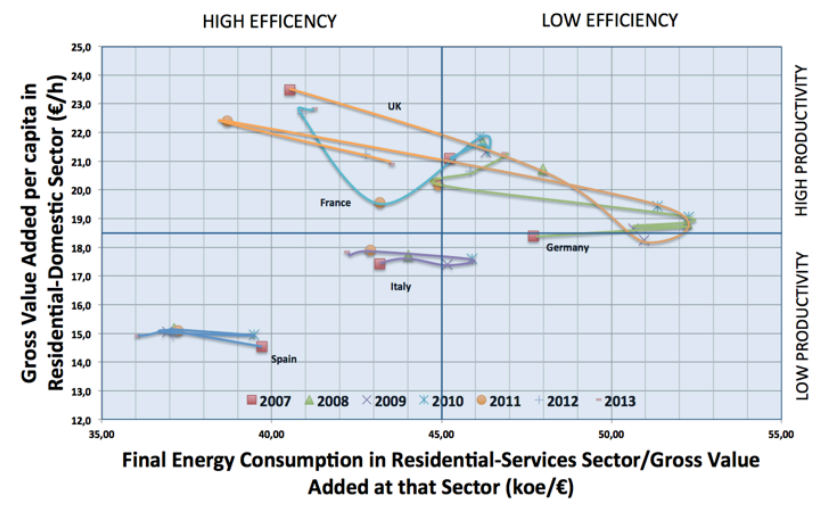

Figure 6. Comparison between Gross Value Added per capita $(€ /$ habitant) and Final Energy Consumption in ResidentialServices/Gross Value Added at that sector (koe/€). Source: Eurostat [6]

\section{B. Industrial Sector}

By making a first approximation to the energy prices of the industrial sector with respect to the contribution of this sector to the GDP, a metric of the situation can be established as illustrated in Figure 7. Interesting conclusions can be drawn, which did not appear in the domestic sector previously analyzed. For the first time there is a trend in the last year 2015 of price reduction in Spain, Italy and Germany. But there are very significant increases in the UK and a little bit less in France. Although these two last countries have a lower participation in the Industrial sector in the GDP, precisely they are the only ones that suffer an increase in the price of electricity, possibly due to the access tariff.

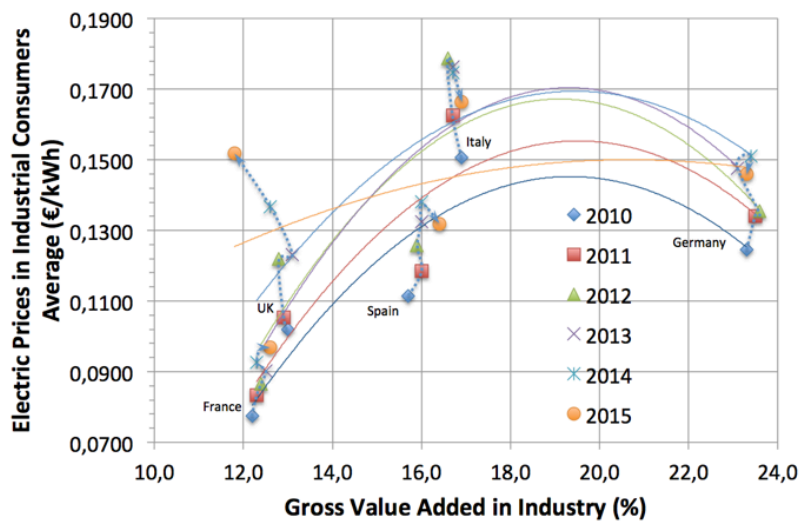

Figure 7. Comparison between Electric Price in Industrial Consumers excluding VAT $(€ / \mathrm{kWh})$ and Share of Industry Sector in GDP (\%). Source: Eurostat [6]
It should be highlighted that there is an approximation of the price of the countries under study in 2015 to the average prices of the industrial sector. This fact should be controled in the coming years, but also a larger period of time should be analyzed to demonstration the trend.

Studing productivity and efficiency together, the aggregate value per capita produced by the industrial sector (including manufacturing and construction) is represented in Figure 8. It has been correlated with the Final Energy Consumption. As it can be seen, the situation in Spain is situated at the extreme of the low efficiency without a clear evolution towards the improvement. France does not have a better position; it is in the same quadrant. Although Italy is in low productivity and efficiency it improves significantly its Efficiency of the energy. Germany is in the best situation with a high productivity of its industrial sector and also with a high efficiency. Finally, United Kingdom always in the quadrant of high productivity moves in 2012 and in 2013 to the quadrant of high efficiency, where it was not in previous years.

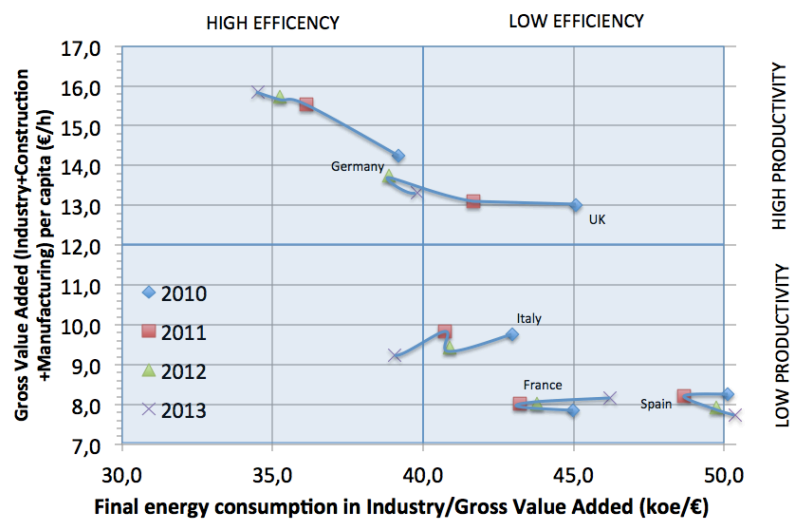

Figure 8. Comparison between Gross Value Added per capita $(€ / \mathrm{h})$ and Final Energy Consumption in Industrial Sector/Gross Value Added at that sector (koe/€). Source: Eurostat [6]

\section{Technical and economical efficiency of the states}

One of the remarkable concepts in the comparison of the performance of process is the efficiency of that process. Thus, the efficiency of a nation's economy can be illustrated by the ratio called 'Energy Intensity of Economy'. This ratio relates the Gross Domestic Product of the country to its energy expenditure: the Gross Inland Consumption. This ratio represents the "economic" efficiency of the country, which will be analized a little later. But another very interesting variable that offers a measure of the "technical" efficiency of the country's energy transformations, that is, how efficiently it transforms the energy consumed by the country (oil, gas, electricity, etc.) from the primary source to final consumption. This is the ratio between the Final Energy Consumption and Gross Inland Consumption. The representation of this last variable in the countries under study is shown below. 


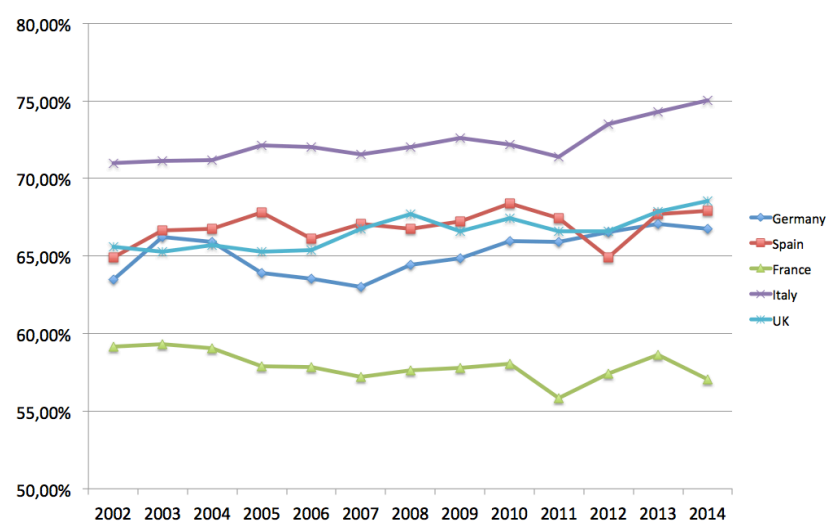

Figure 9. Final Energy Consumption/Gross Inland Consumption (\%). Source: Eurostat [6]

In the figure above it can see the very favorable situation of Italy, whose energy transformations are very efficient. The performance of their energy supply, efficiency in their distribution networks and electric power transport, their model of transport and mobility, its model of energy mix and generation and distribution of gas and electricity produce a very high technical efficiency ratio compared to other countries. On the other hand, France presents the lowest value of efficiency, remaining the rest in an intermediate band.

Regarding to the 'Energy Intensity of Economy' ratio, it can be analysed in comparison with the country's productivity (per capita income) as shown in Figure 10. As can be seen, UK and Italy have the most positive ratios of Economic Efficiency of the country. In contrast Spain, with good prospects from the services sector, has the lowest Efficiency. Finally, although a positive evolution, Germany and France with also a high productivity in their generation of economic value, have a low Efficiency from the point of view of the same economic area.

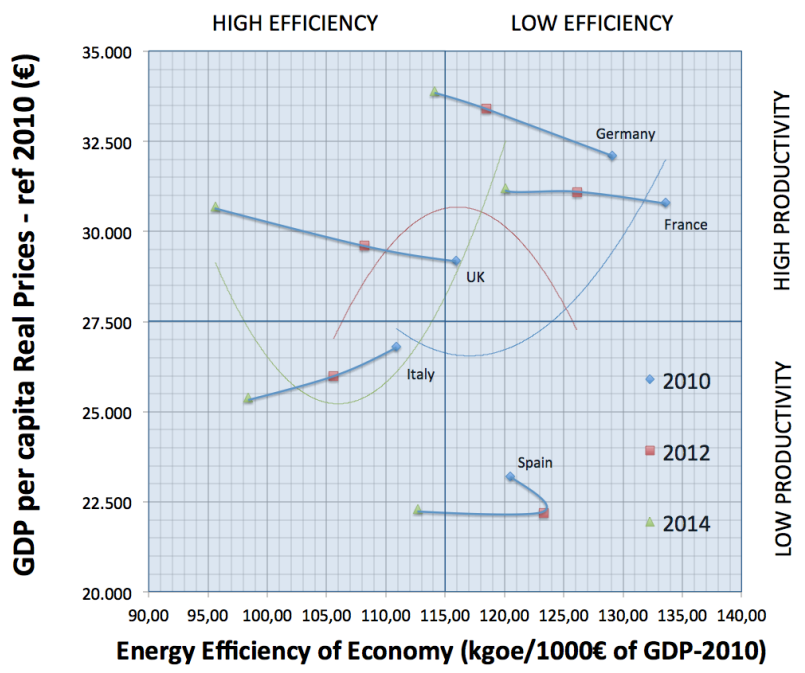

Figure 10. Comparison between Energy Efficiency of Economy (koe/1000€) and GDP per capita $(€ / \mathrm{h})$

In figure 11, it has been correlated the two efficiency ratios: the relation between the economic with the Energy Intensity of Economy and the technique with the Final Energy Consumption/Gross Inland Consumption ratio. It can be seen that Italy is placed in the optimal quadrant and
France in the worst situation. The remaining countries would be in the middle band of technical efficiency, all evolving towards high efficiency in their economy. Comparing the two ratios, it can observed a correspondence of the behaviour of the countries in the fulfillment of one and another ratio. That is to say, if a country is efficient from the point of view of the Economic Efficiency measured by the variable Energy Efficiency of Economy (Gross Inland Consumption / GDP), it will also have a good value of technical efficiency (GIC / FEC) and vice versa. But also, a country with low productivity in one of the sectors or low efficiency of its economy in any of these sectors will have low energy and technical efficiencies.

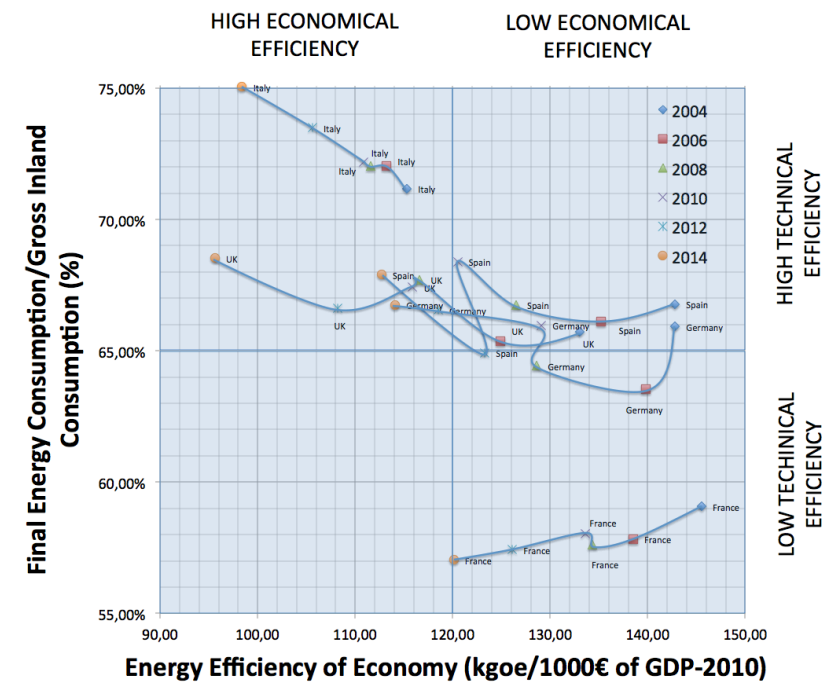

Figure 11. Comparison between Energy Efficiency of Economy (koe/1000€ of GDP) and Final Energy Consumption/Gross Inland Consumption (\%). Source: Eurostat [6]

In Table 1, it can be seen the correspondences of each of the countries analyzed. Italy and the UK, two of the countries arround average productivity of the countries studied, present the best result in technical and Economic Efficiency. Germany, the most productive country, presents a low result in efficiency together, as Spain, the least productive. France is the worst case, with very low technical efficiency; its Economic Efficiency has a tendency to improve but is insufficient. In addition, it is the country whith the lowest prices of electricity and gas.

Table 1. Efficiency results and his relation with Energy Efficiency of Economy (economic efficiency) and Final Energy Consumption/Gross Inland Consumption (technical efficiency)

\begin{tabular}{|c|c|c|c|c|c|c|c|}
\hline & \multicolumn{3}{|c|}{$\begin{array}{c}\text { EFFICIENCY OF ECONOMY } \\
\text { (FECS/GDPs) }\end{array}$} & \multicolumn{2}{|c|}{$\begin{array}{l}\text { PRODUCTIVITY } \\
\text { (GDPs/h) }\end{array}$} & \multirow{2}{*}{$\begin{array}{l}\text { Economical } \\
\text { Efficiency EIE } \\
\text { (koe/1000€) }\end{array}$} & \multirow{2}{*}{$\begin{array}{l}\text { Technical } \\
\text { Efficiency } \\
\text { GIC/FEC }\end{array}$} \\
\hline & Services & Industrial & Transport & Services & Industrial & & \\
\hline Germany & High cons. & High cons. & & & & & \\
\hline Spain & Low cons. & & & & & & \\
\hline France & High cons. & & & & & & \\
\hline Italy & Low cons. & & & & & & \\
\hline UK & & & & & & & \\
\hline
\end{tabular}

\section{Conclusion}

The analysis of the services sector and the industrial sector, comparing electric energy with the productivity of a country (income per capita), enables strategies to improve productivity using policies of reduction of prices 
of the access tariff. In addition, there are alternative sources of electricity to improve productivity. Spain can improve the productivity and competitiveness of the economy, especially in the services sector, increasing the use of gas natural as an alternative to electricity due to its low price per $\mathrm{kW} / \mathrm{h}$.

The energy policies carried out through the Access Tariff have allowed maintaining the competitiveness of the industrial sector. Although in countries like UK there is little margin [12] through the tariff, these policies allow the sustained development of the sector.

Moreover, it is produced a progressive increase in productivity as the size of the company increases. It is significant that Spain, France and Italy have 4\% of companies with more than 10 workers, whereas United Kingdom and Germany the percentage increases to 9 and $12 \%$ respectively. Fundamentally in the industrial sector, a larger company size facilitates access to credit, generates economies of scale and synergies that allow a greater robustness of the productive system.

The situation of high productivity and energy efficiency in the industrial sector, as in Germany, does not ensure that the ratios of technical and Economic Efficiency studied in this article are optimal. It is more important to ensure that all sectors keep a balance in efficiency to get good ratios. But also, a country with low productivity in one of the sectors or low efficiency of its economy in any of these sectors will have a lower energy and technical efficiencies.

In conclusion, a country with high productivity and very competitive in terms of energy prices, may not have good ratios of efficiency in its economy, or even could not have a good technical efficiency. In oher words, the problem is not improving productivity, or competitiveness, the problem is how better results could be reached improuving parameters such as: the infrastructure design, energy supply performance, efficiency in electricity distribution and transport networks, transport and mobility model, model of energy mix and generation and distribution of gas and electricity, but also studing how efficient the country is in other sectors in energy consumption, which ultimately affects those global parameters that must define the global energy strategies and policies of the states.

\section{References}

[1] Políticas de la Unión Europea: Energía. Comisión Europea. Dirección General de Comunicación - ISBN 978-92-79-42193-8 - Noviembre de 2014

[2] EU Reference Scenario 2016 Energy, Transport And Ghg Emissions Trends To 2050. EUROPEAN COMMISSION Directorate-General for Energy, DirectorateGeneral for Climate Action and Directorate-General for Mobility and Transport - ISBN 978-92-79-52374-8 - Julio 2016

[3] A. Martinez, S. Valero, E. Velasco, "Sustainability as a Paradigm of Energy Policy" Renewable Energy and Power Quality Journal (RE\&PQJ) ISSN 2172-038X, no14, May 2016

[4] Naredo, J. M. (1996). Sobre el origen, el uso y el contenido del término sostenible. En T. y. Ministerio de Obras Públicas, La construcción de la ciudad sostenible. Madrid.

[5] CIA [on-line] Central Ingelligence Agency - The World Factbook [Consulted 2013]. Available at: https://www.cia.gov/library/publications/the-worldfactbook/fields/2012.html

[6] EUROSTAT [on-line] - European Commision Statistics Database - [Consulted 2016]. Available at: http://epp.eurostat.ec.europa.eu/portal/page/portal/eurostat/hom e/

[7] WEC [on-line] Energy Trilemma Index. Benchmarking the sustainability of national energy systems. World Energy Council. London: World Energy Council - (2014) Available at : http://www.worldenergy.org

[8] EISD [on-line] Energy Indicators for Sustainable Development: Guidelines and Methodologies. IAEA-UNDESAIEA-EUROSTAT-EEA. (2005). Vienna: IAEA

[9] Vera, I. (2005). Indicators for sustainable energy development: an initiative by the International Atomic Energy Agency. Natural Resources Forum, 274-283.

[10] A. Martinez, S. Valero, E. Velasco, "Energy intensity of the economy as a variable to measure the energy efficiency of a country: comparison between European member states" Renewable Energy and Power Quality Journal (RE\&PQJ) ISSN 2172-038X, nº 12, Abril 2014

[11] IMF [on-line] International Monetary Fund - World Economic Outlook Databases (WEO) [Consulted 2013]. Available at: http://www.imf.org/external/data.htm

[12] A. Martinez, S. Valero, E. Velasco, "Trends in electricity prices and their relation to the competitiveness and efficiency in EU countries" Renewable Energy and Power Quality Journal (RE\&PQJ) ISSN 2172-038X, nº13, Abril 2015 